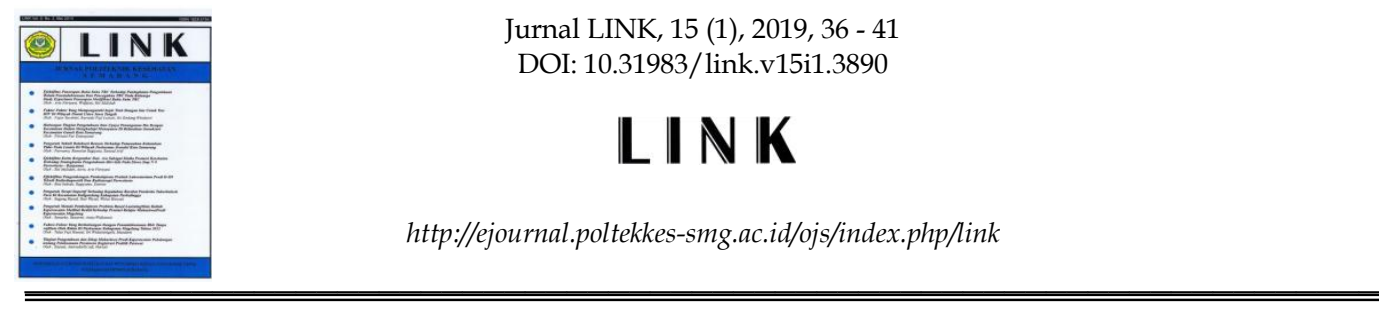

\title{
PENINGKATAN KAPASITAS IBU-IBU ARISAN SEBAGAI INISIATOR GERAKAN MASYARAKAT CERDAS MENGGUNAKAN OBAT (GEMA CERMAT)
}

\author{
Sarmalina*) ; Sarmadi ; Mona Rahmi ; Sonlimar Mangunsong \\ Jurusan Farmasi ; Poltekkes Kemenkes Palembang \\ Jl. Jenderal Sudirman KM 3,5 Nomor 1365 ; Palembang
}

\begin{abstract}
Abstrak
Penggunaan obat yang benar menjadi kunci keberhasilan terapi. Obat memiliki dosis, cara penggunaan, aturan pakai, aturan penyimpanan dan peringatan yang berbeda-beda, sehingga masyarakat perlu memiliki bekal pengetahuan yang benar, sehingga dapat menggunakan obat dengan benar. Ibu-ibu arisan adalah sekelompok ibu-ibu yang secara periodik bertemu dan memiliki potensi menjadi penggerak atau panutan bagi masyarakat disekitarnya dalam berbagai hal, apabila mereka memiliki pengetahuan dan keterampilan yang memadai, maka mereka dapat membantu keluarga, teman dan masyarakat disekitarnya untuk bertindak benar. Kegiatan pengabdian kepada masyarakat ini bertujuan untuk melatih keterampilan ibu-ibu arisan dalam memilih dan menggunakan obat dengan benar. Kegiatan ini akan diikuti oleh perwakilan dari beberapa kelompok arisan. Setiap ibu akan melakukan diseminasi tentang materi yang sama di setiap kelompok arisannya. Peserta berjumlah 15 orang berasal dari 8 kelompok arisan yang berbeda. Ibu-ibu dilatih tentang penggunaan dan keterampilan memilih obat. Pengetahuan ibu-ibu peserta meningkat dari rata-rata $65 \%$ menjadi $95 \%$ setelah mendapat penjelasan mengenai penggunaan obat. Dengan demikian maka penyebaran informasi yang bertujuan memberdayakan masyarakat agar cerdas dalam menggunakan obat lebih cepat tercapai dan cakupan wilayahnya lebih luas.
\end{abstract}

Kata kunci : Ibu-ibu; Pengetahuan; Obat

\begin{abstract}
[INCREASING CAPACITY OF REGULAR SOCIAL GATHERING MOTHERS AS INITIATORS INTELLIGENT COMMUNITY RATIONALE USE OF MEDICINE (ICO RUM)] The use of the right drug is the key to the success of therapy. Drugs have different dosages, methods of use, rules of use, rules of storage and warnings, so that people need to have the right knowledge, so they can use drugs correctly. Regular social gathering mothers is a group of mothers who periodically meet and have the potential to be role model for the surrounding community in various ways, if they have adequate knowledge and skills, they can help their families, friends and communities around them to act right. This community service activity aims to train the skills of the regular social gathering women in choosing and using drugs correctly. This activity will be attended by representatives from several social gathering groups. Each mother will disseminate the same material in each groups. Participants totaling 15 people came from 8 different groups. Mothers are trained in the use and skills of choosing drugs. Knowledge of participants mothers increased from an average of $65 \%$ to $95 \%$ after receiving an explanation of drug use. Thus the dissemination of information aimed at empowering people to be smart in using drugs is more quickly achieved and the scope of their territory is wider.
\end{abstract}

Keywords: Mothers ; Knowledge ; Drug

\footnotetext{
*) Sarmalina Sarmalina

E-mail: sarmalina82@gmail.com
} 


\section{Pendahuluan}

Program Indonesia sehat yang digagas oleh pemerintah saat ini memiliki tujuan agar setiap orang sehat dapat memelihara dan meningkatkan kesehatannya, sementara yang sakit dapat mempercepat kesembuhannya. Peningkatan kesehatan dilakukan melalui upaya promotif dan preventif, melalui pendekatan komunitas, namun tidak mengabaikan upaya kuratif dan rehabilitatif (Inpres, 2017). Upaya kuratif dan rehabilitatif masih sangat mendapat perhatian, salah satunya melalui kemudahan akses terhadap pelayanan kesehatan yang komprehensif.

Masyarakat harus memiliki paradigma hidup sehat, yang dibangun melalui pemberdayaan dan kemandirian masyarakat. Prinsip paradigma sehat mendorong seluruh pemangku kepentingan untuk berkomitmen dalam upaya mencegah dan mengurangi risiko kesehatan yang dihadapi individu, keluarga, kelompok dan masyarakat (Kemenkes, 2016). Pendekatan melalui keluarga dilakukan melalui berbagai perangkat seperti pendataan keluarga, profil kesehatan keluarga, konseling, kunjungan rumah dan pemberdayaan masyarakat.

Obat harus digunakan dengan tepat agar memberi manfaat terapi yang optimal. Di pasaran terdapat berbagai jenis zat aktif untuk mengatasi berbagai macam penyakit, dari merek dagang maupun generik. Bentuk sediaannya antara lain tablet, tablet salut, tablet lepas lambat, capsul, capsul lunak, sirup, suspensi, suppositoria, inhaler dan lain lain. Masing-masing obat memiliki dosis, cara dan aturan pakai, serta penyimpanan yang berbeda beda.

Saat menerima obat di Puskesmas, atau saat membeli obat di apotek, toko obat bahkan di warung, sering kali orang tidak mendapat penjelasan yang memadai dan tidak memanfaatkan kesempatan itu untuk bertanya. Sehingga masih banyak ditemukan penggunaan obat yang tidak tepat. Penggunaan obat yang tidak tepat dapat berdampak kepada kerugian baik secara klinik maupun ekonomi .
Kerugian secara klinik misalnya, menggunakan obat-obat antiagregasi platelet sebelum makan, akan menyebabkan iritasi lambung (Dipiro, 2008). Ketidaktepatan lainnya adalah menggunakan obat antasida sesaat sesudah makan, tidak memberikan manfaat. Kerugian secara ekonomi adalah masa penyembuhan menjadi lebih lama, biaya pengobatan bertambah atau menjadi lebih mahal.

Pemerintah melalui Direktorat Jenderal Bina Kefarmasian dan Alat Kesehatan dalam rangkaian Gerakan Masyarakat Hidup Sehat, juga mencanangkan Gerakan Masyarakat Cerdas Menggunakan Obat "Gema Cermat" (Rakornas, 2017). Melalui gerakan ini diharapkan setiap masyarakat memiliki kemandirian dalam penggunaan obatnya. Kemandirian itu diperoleh melalui pemberdayaan yang dapat diupayakan melalui peningkatan pengetahuan dan, perbaikan perilaku. Gerakan ini melibatkan setiap komponen masyarakat termasuk Ibu-Ibu.

Salah satu kearifan lokal bangsa Indonesia adalah adanya kelompok Ibu-ibu Arisan. Kelompok ini merupakan wadah bagi kaum ibu untuk menjalin silaturahmi sekaligus dimanfaatkan sebagai ajang tukar menukar informasi antara sesame anggota. Ibu adalah orang yang paling berperan dalam menentukan dan mengatur penggunaan obat ditengah keluarga, maka akan sangat baik bila seorang ibu memiliki pengetahuan dan keterampilan yang cukup tentang hal itu. Hal ini akan meningkatkan efektifitas dan efisiensi dalam penggunaan obat, bahkan dapat mencegah terjadinya "medication error".

Oleh karena itu setiap ibu perlu diberdayakan, mulai dari dirinya, lalu menjangkau komunitasnya. Diharapkan setiap ibu dapat menjadi inisiator baik ditengah keluarga maupun di lingkungan sekitarnya. Hal ini dapat dilakukan juga dalam lingkup yang lebih luas. Pemberdayaan ini dapat dilakukan dengan berbagi cara, diantaranya melalui pelatihan (Quick JD., dkk 1997).

Direktorat Jenderal Bina Kefarmasian dan Alat Kesehatan telah menerbitkan buku saku dalam bentuk 
elektronik yang berisi informasi mengenai berbagai hal berkaitan dengan penggunaan obat. Buku ini akan dijadikan acuan pembuatan buku saku, dicetak dan dibagikan kepada setiap perwakilan Ibu-ibu arisan yang dilatih. Penjelasan tentang materi yang terdapat dalam buku akan dilakukan oleh team saat dilakukannya pertemuan.

\section{Metode}

Kegiatan ini melibatkan 8(delapan) kelompok arisan, dimana setiap kelompok mengirimkan 2 orang perwakilannya untuk dilatih menjadi inisiator Gema Cermat. Pelatihan terhadap ibu-ibu ini dilakukan dalam beberapa tahap, yaitu: (1) Metode ceramah, dilakukan dengan menjelaskan tentang berbagai aspek yang perlu diperhatikan terkait penggunaan obat; (2) Metode peragaan, dilakukan dengan memperagakan cara penggunaan berbagai bentuk sediaan obat; (3) Metode simulasi, dilakukan untuk memperagakan kemampuan ibu-ibu dalam memilih jenis obat dan membaca petunjuk yang tertera pada kemasan dan brosur.

Disamping pelatihan, kepada semua peserta dibagikan buku saku untuk digunakan sebagai alat bantu dalam mensosialisasikan gerakan cerdas menggunakan obat. Untuk mengukur keterserapan informasi yang diberikan digunakan instrument kuisioner pre dan post-test, sedangkan untuk menilai inisiatif para ibu sebagai inisiator di kelompoknya, tim melakukan observasi dengan formulir chek-list saat acara arisan berlangsung disetiap kelompok arisan. Para ibu peserta diminta untuk selalu berkoordinasi dengan tim memalui media whats-app group, sehingga bila diperlukan team dapat membantu para ibu dalam memberi informasi seputar penggunaan obat

\section{Hasil dan Pembahasan}

Sebelum diberikan edukasi untuk membekali peserta dengan pengetahuan dan keterampilan terkait penggunaan obat, mereka diminta untuk menjawab beberapa pertanyaan tertulis.
Tabel 1. Distribusi Frekuensi Pengetahuan Peserta Sebelum Edukasi

\begin{tabular}{llcc}
\hline No & Pertanyaan & $\begin{array}{c}\text { Jawaban } \\
\text { benar } \\
\text { (n) }\end{array}$ & $\begin{array}{c}\text { Jawaban } \\
\text { Salah } \\
\text { (n) }\end{array}$ \\
\hline 1 & $\begin{array}{l}\text { Penggunaan } \\
\text { antibiotik untuk } \\
\text { batuk dan flu }\end{array}$ & 8 & 7 \\
\hline 2 & $\begin{array}{l}\text { Penandaan untuk } \\
\text { antibiotik }\end{array}$ & 8 & 7 \\
\hline 3 & $\begin{array}{l}\text { Lama } \\
\text { penggunaan } \\
\text { antibiotik }\end{array}$ & 13 & 2 \\
\hline 4 & $\begin{array}{l}\text { Aturan pakai } \\
\text { obat }\end{array}$ & 9 & 6 \\
\hline 5 & $\begin{array}{l}\text { Waktu } \\
\text { penggunaan obat } \\
\text { maag dan obat } \\
\text { mual }\end{array}$ & 13 & 2 \\
\hline 6 & $\begin{array}{l}\text { Aturan untuk } \\
\text { jenis tablet salut }\end{array}$ & 7 & 8 \\
\hline 7 & $\begin{array}{l}\text { Pelarut untuk } \\
\text { jenis obat puyer }\end{array}$ & 14 & 1 \\
\hline 8 & $\begin{array}{l}\text { Aturan untuk } \\
\text { obat jenis } \\
\text { suspense }\end{array}$ & 5 & 10 \\
\hline 9 & $\begin{array}{l}\text { Penggunaan obat } \\
\text { jenis suppositoria }\end{array}$ & 7 & 8 \\
\hline 10 & $\begin{array}{l}\text { Tempat } \\
\text { penyimpanan } \\
\text { obat }\end{array}$ & 13 & 2 \\
\hline & Jumlah total & $\mathbf{9 7}$ & $\mathbf{5 3}$ \\
\hline & & & \\
\hline & & \\
\hline
\end{tabular}

Latar belakang peserta yang mengikuti kegiatan ini kebanyakan adalah SMA, hanya satu orang yang lulusan SMP dan dua orang lulusan perguruan tinggi. Dari hasil pre-test, pengetahuan peserta akan obat dan penggunaannya tidak terlalu rendah. Secara rata-rata dari sepuluh pertanyaan $65 \%$ dapat dijawab dengan benar. Separuh dari peserta masih kurang memahami tentang tujuan penggunaan dan penandaan antibiotik, namun pada umumnya sudah mengetahui kalau antibiotik harus diminum sampai habis.

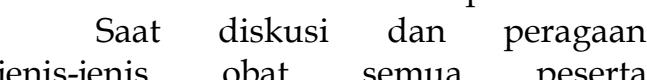
mengatakan kalau mereka masih kurang mengenal perbedaan jenis tablet salut dengan tablet biasa, sehingga mereka berpikir bahwa kalau ingin dosis yang kecil maka setiap tablet dapat dipatahkan menjadi dua bagian, atau bahkan dihancurkan. Demikian juga dengan perbedaan suspensi dengan sirup serta perbedaan suppositoria dengan ovula.

Setelah melakukan pre-test peserta 
mendengarkan penjelasan tentang tujuan kegiatan gerakan masyarakat cerdas menggunakan obat serta materi tentang penggunaan obat. Penjelasan disampaikan dengan bahasa yang sederhana sehingga mudah dipahami oleh peserta. Kemudian dilanjutkan dengan peragaan untuk memperkenalkan berbagai bentuk sediaan obat, baik obat generik maupun obat dengan merek dagang. Peserta mengamati langsung obatnya dengan dibantu oleh mahasiswa.

Selanjutnya dilakukan simulasi peran oleh seluruh peserta yang dibagi dalam beberapa kelompok. Tiap kelompok diberi kasus yang berbeda, dan setiap ibu diminta untuk dapat memilih obat yang diminta dan memberikan penjelasan atas pertanyaan yang diberikan oleh teman satu kelompoknya. Capaian pelatihan yang diikuti oleh perwakilan kelompok arisan ini diukur dengan kuisioner post-test. Hasil di tabel 2 berikut ini.

Tabel 2. Distribusi Frekuensi Pengetahuan Peserta Sesudah Edukasi

\begin{tabular}{llcc}
\hline No & Pertanyaan & $\begin{array}{c}\text { Jawaban } \\
\text { benar } \\
\text { n }\end{array}$ & $\begin{array}{c}\text { Jawaban } \\
\text { Salah } \\
\text { n }\end{array}$ \\
\hline 1 & $\begin{array}{l}\text { Penggunaan } \\
\text { antibiotik untuk } \\
\text { batuk dan flu }\end{array}$ & 14 & 1 \\
\hline 2 & $\begin{array}{l}\text { Penandaan untuk } \\
\text { antibiotic }\end{array}$ & 13 & 2 \\
\hline 3 & $\begin{array}{l}\text { Lama penggunaan } \\
\text { antibiotik }\end{array}$ & 15 & 0 \\
\hline 4 & Aturan pakai obat & 15 & 0 \\
\hline 5 & $\begin{array}{l}\text { Waktu penggunaan } \\
\text { obat maag dan obat } \\
\text { mual }\end{array}$ & 15 & 0 \\
\hline 6 & $\begin{array}{l}\text { Aturan untuk jenis } \\
\text { tablet salut }\end{array}$ & 15 & 0 \\
\hline 7 & $\begin{array}{l}\text { Pelarut untuk jenis } \\
\text { obat puyer }\end{array}$ & 15 & 0 \\
\hline 8 & $\begin{array}{l}\text { Aturan untuk obat } \\
\text { jenis suspensi }\end{array}$ & 14 & 1 \\
\hline 9 & $\begin{array}{l}\text { Penggunaan obat } \\
\text { jenis suppositoria }\end{array}$ & 12 & 3 \\
\hline 10 & $\begin{array}{l}\text { Tempat } \\
\text { penyimpanan obat }\end{array}$ & 15 & 0 \\
\hline Jumlah total & $\mathbf{1 4 3}$ & $\mathbf{7}$ \\
\hline & & \\
\hline
\end{tabular}

Pengetahuan peserta meningkat dari rata-rata $65 \%$ menjadi $95 \%$ setelah edukasi. Namun ada peserta yang belum dapat mengingat penandaan antibiotik sebagai obat keras dan perbedaan suppositoria dengan ovula. Setelah pembekalan peserta melanjutkan kegiatan berbagi informasi di lingkungannya, di arisan, setelah kegiatan pengajian atau kegiatan lainnya. Kegiatan ini diobservasi oleh team yang melibatkan mahasiswa. Hasilnya disajikan dalam tabel berikut ini.

Tabel 3. Distribusi Frekuensi Aktifitas Inisiator Gema Cermat

\begin{tabular}{llcc}
\hline No & \multicolumn{1}{c}{ Aktifitas } & \multicolumn{2}{c}{ Keterangan } \\
& & Ya & Tidak \\
\hline 1 & $\begin{array}{l}\text { Menjelaskan } \\
\text { tentang cara } \\
\text { penggunaan obat } \\
\text { dengan baik }\end{array}$ & 6 & 2 \\
& Melakukan diskusi & 8 & 0 \\
\hline 2 & $\begin{array}{l}\text { Menggunakan } \\
\text { buku saku sebagai } \\
\text { alat bantu }\end{array}$ & 8 & 0 \\
\hline 4 & $\begin{array}{l}\text { Melakukan } \\
\text { peragaan } \\
\text { menggunakan } \\
\text { kemasan obat }\end{array}$ & 6 & 2 \\
\hline & & \\
\hline & Total & $\mathbf{2 8}$ & $\mathbf{4}$ \\
\hline
\end{tabular}

Secara keseluruhan kegiatan berbagi informasi tentang penggunaan obat sudah berjalan dengan baik. Semua sudah melakukan tugasnya seperti yang diharapkan, namun masih ada dua kelompok yang belum menjelaskan cara penggunaan obat dengan baik. Lalu ada dua kelompok yang tidak membawa kemasan obat untuk alat peraganya sehingga kurang memuaskan. Inisiator membagikan buku saku kepada rekannya.

Gerakan masyarakat cerdas menggunakan obat muncul dari keprihatinan akan rendahnya pengetahuan masyarakat dalam hal penggunaan obat dengan benar. Berbagai masalah dapat timbul akibat penggunaan obat yang tidak benar. Berdasarkan Hasil Riset Kesehatan Dasar (Riskesdas, 2013) menunjukkan bahwa 35,2\% rumah tangga menyimpan obat untuk swamedikasi. Dari 35,2\% rumah tangga yang menyimpan obat, $35,7 \%$ di antaranya menyimpan obat keras. Dari keluarga yang menyimpan obat di rumah, terdapat $27,8 \%$ diantaranya yang menyimpan antibiotik. Kebanyakan antibiotik tersebut diperoleh dengan cara membeli tanpa resep dokter $(86,1 \%)$.

Penggunaan antibiotik yang tepat 
tentu tidak akan menimbulkan masalah, namun kenyataannya di banyak tempat obat ini digunakan secara tidak tepat. Pemakaian antibiotik untuk batuk dan pilek non-pneumonia masih banyak terjadi, baik dilakukan oleh masyarakat yang membeli antibiotik oral di apotek tanpa resep, maupun akibat peresepan yang dilakukan oleh perawat, bidan bahkan dokter di beberapa Puskesmas. Pemakaian antibiotik secara sembarangan berpotensi menyebabkan terjadinya resistensi. Di Dhaka, pada tahun 2012 resistensi terhadap beberapa antibiotik yang sering digunakan secara bebas, yaitu ciproloxacin, cotrimoksazol, kloramfenikol, cefixime, ampicilin dan azitromycin (Begum dkk, 2015).

Pemilihan antibiotik juga harus tepat, sebab jika tidak hal ini menjadi faktor penyebab kegagalan terapi (Dipiro, 2008). Orang yang dapat memilihkan antibiotik dengan tepat adalah dokter, oleh karena itu antibiotika hanya dapat digunakan atas dasar resep dokter. Aturan pakai obat juga masih merupakan hal yang belum dipahami dengan baik oleh sebagian peserta. Contohnya aturan pakai obat tiga kali sehari, dianggap bahwa yang penting obat tersebut diminum sebanyak tiga kali dalam waktu yang berbeda. Interval satu waktu dengan waktu penggunaan berikutnya tidak perlu diperhatikan. Untuk penggunaan obat-obatan terutama golongan anti-mikroba, interval pemberian obat sangat penting diperhatikan karena efek terapi sangat ditentukan oleh konsentrasi obat dalam darah.

Penjelasan mengenai aturan pakai obat terdapat juga di dalam buku saku Cara Penggunaan Obat yang diterbitkan oleh Kemenkes, yang dibagikan kepada peserta. Selain aturan pakai, waktu minum obat, pelarut yang digunakan untuk melarutkan obat puyer juga merupakan informasi yang sangat perlu diketahui oleh masyarakat. Ini merupakan topik yang juga banyak ditanyakan oleh peserta saat berdiskusi.

Sebelum edukasi pengetahuan peserta terkait jenis sediaan tablet salut juga masih belum memadai. Selain tablet biasa, terdapat juga tablet salut gula, salut selaput atau salut enterik. Formulasi khusus ini memiliki tujuan yang berbeda. Bila bahan aktif obat diharapkan untuk larut dan diabsorbsi di usus maka formulasinya dibuat bersalut selaput atau salut enterik. Obat jenis ini tidak boleh dikunyah, dihancurkan atau dipatahkan, sebab dapat merusak formulanya sehingga tujuan terapi tidak tercapai dengan optimal ( IAI, 2014).

Peserta yang sudah mendapatkan informasi baik melalui pembekalan maupun melalui buku saku yang dibagikan, selanjutnya melakukan kegiatan berbagi informasi juga di kelompok arisannya. Dalam hal ini peserta dianggap menjadi inisiator "Gerakan Cerdas Menggunakan Obat", sebab mereka telah berinisiatif menjadi penggerak di lingkungannya unuk menggunakan obat secara benar. Gerakan ini mendukung Gerakan Masyarakat Sehat (Germas) melalui upaya pencapaian Program Indonesia Sehat melalui pendekatan keluarga (Kemenkes, 2016). Kegiatan peserta dalam menyampaikan informasi diobservasi oleh pelaksana. Tentu kegiatan menginisiasi anggota kelompok arisan lainnya ini penuh dengan keterbatasan, terutama dalam melakukan peragaan penggunaan obat karena terbatasnya jenis obat-obatan yang dimilikinya. Namun demikian, patut diapresiasi kemauan ibu-ibu tersebut berbagi informasi kepada teman-temannya. Diharapkan melalui kegiatan seperti ini mereka akan sangat peduli dan selalu berhati-hati dalam penggunaan obat, sehingga selalu mencari informasi yang benar agar tidak mengalami masalah saat menggunakan obat. Melalui kegiatan ini tim pelaksana pengabdian masyarakat juga membuka akses kepada peserta dan anggota kelompok arisannya jika ada informasi yang dibutuhkan terkait obat, baik secara langsung, maupun melalui media komunikasi yang tersedia.

\section{Simpulan dan Saran}

Kegiatan pengabdian masyarakat ini telah memberikan pengetahuan dan keterampilan bagi beberapa orang ibu sehingga mereka menjadi lebih cerdas 
dalam penggunaan obat. Kecerdasan yang dimiliki oleh ibu-ibu peserta juga sudah dibagikan kepada rekannya, sehingga lebih banyak lagi ibu-ibu yang cerdas dalam menggunakan obat.

\section{Ucapan Terima Kasih}

Terima kasih disampaikan kepada Poltekkes Kemenkes Semarang yang telah memberikan kesempatan kepada penulis untuk mempublikasikan di jurnal ini. Ucapan terima kasih juga kami sampaikan kepada pihak-pihak yang membantu pelaksanaan penelitian.

\section{Daftar Pustaka}

Begum, A., MdS, Bari., FR Chowdhury., N.Ahmed, KAR Sayeed. Pattern of Anti-Microbial Sensitivity and Resistance against Salmonella Species in a Tertiary Hospital in Dhaka. Journal of Enam Medical College. 2015 ; Vol 5 No 2 (www.banglajolinfo.)

Dipiro Y.T., et al. (2008). Pharmacoteraphy Pathophysiologic Approach, seventh edition.Mc Graw Hill Medical, New York (e-book)

IAI. (2014). Informasi Spesialite Obat Indonesia, Volume 49. Ikatan Apoteker Indonesia, PT.ISFI Penerbitan, Jakarta

Inpres. (2017). Instruksi Presiden Republik Indonesia Nomor 1 Tahun 2017 Tentang Gerakan Masyarakat Hidup Sehat, Jakarta

Kemenkes RI. (2016). Peraturan Menteri Kesehatan Republik Indonesia Nomor 39 Tahun 2016 Tentang Pedoman Penyelenggaraan Program Indonesia Sehat Dengan Pendekatan Keluarga. Kementerian Kesehatan Republik Indonesia, Jakarta.

Kemenkes RI. (2016). Peraturan Menteri Kesehatan Republik Indonesia Nomor 73 Tahun 2016 Tentang Standar Pelayanan Kefarmasian Di Apotek. Kementerian Kesehatan Republik Indonesia, Jakarta.

Quick JD, Rankin JR., Laing RO., dkk (1997). Managing Drug Supply, Edisi kedua, Management
Sciences for Health in Collaboration with the World Health Organization. Kumarian Press, Connecticut, USA

Rakornas. (2017). Rapat Koordinasi Nasional Farmalkes, 8-10 Maret 2017. Medan. Direktur Jenderal Kefarmasian dan Alat Kesehatan, Kementerian Kesehatan RI 